\title{
Closely Mounted Compact Wideband Diversity Antenna for Mobile Phone Applications
}

\author{
Bunggil Yu, ${ }^{1}$ Chang Won Jung, ${ }^{2}$ Haechun Lee, ${ }^{3}$ Myun-Joo Park, ${ }^{4}$ Byeongkwan Kim, ${ }^{4}$ \\ Hyunho Wi, ${ }^{4}$ Yonggyu Choi, ${ }^{4}$ Deokyun Kim, ${ }^{4}$ and Byungje Lee ${ }^{4}$ \\ ${ }^{1}$ Communication R\&D Center, Samsung Thales Co., Seongnam-Si, Gyeonggi-Do, 463-870, Republic of Korea \\ ${ }^{2}$ Graduate School of NID Fusion Technology, Seoul National University of Technology, 172 Gongneung-2 Dong, Nowon-Gu, \\ Seoul 139-743, Republic of Korea \\ ${ }^{3}$ Department of Electric Energy System, Korea Polytechnic College II, 448-56, Munemiro, Gusan-Dong, Bupyeong-Gu, \\ Incheon 403-719, Republic of Korea \\ ${ }^{4}$ Department of Wireless Communications Engineering, Kwangwoon University, 447-1 Wolgye-Dong, Nowon-Gu, \\ Seoul 139-701, Republic of Korea
}

Correspondence should be addressed to Byungje Lee, bj_lee@kw.ac.kr

Received 6 January 2012; Accepted 13 March 2012

Academic Editor: Seong-Youp Suh

Copyright () 2012 Bunggil Yu et al. This is an open access article distributed under the Creative Commons Attribution License, which permits unrestricted use, distribution, and reproduction in any medium, provided the original work is properly cited.

\begin{abstract}
Here a compact wideband diversity antenna covering the PCS/UMTS/WiMAX bands with high isolation and low enveloped correlation coefficient (ECC) is proposed. To widen the bandwidth, the proposed antenna uses a structure with a gap-coupled feed and an inductively shorted line that has capacitive compensation between the radiator and the ground plane. Also, a suspended line with a parasitic element is used to enhance the isolation between the two antennas.
\end{abstract}

\section{Introduction}

The implementation of antenna diversity is a well-known technique for enhancing the performance of wireless communication systems since it reduces multipath fading and cochannel interference [1]. However, mutual coupling between antennas degrades their performance. Consequently, various methods have been studied to enhance isolation between antennas within the limited space of mobile phones, including the protruded T-shape ground $[2,3]$, the quarter wavelength slot on the ground $[4,5]$, and the jointed shorting and suspended line [6-8]. These methods can effectively reduce the mutual coupling between antennas, but they occupy large spaces and provide narrow bandwidth. The diversity antenna of a mobile phone requires low profile and low cost while maintaining a wide bandwidth, good isolation, and a low correlation coefficient. The correlation coefficient, which is closely related to interantenna isolation, is the most important factor to be considered in the design of a diversity antenna.
In this paper, a compact wideband diversity antenna with an impedance bandwidth of $45 \%$ is proposed. This design is accomplished through use of a capacitive gap-coupled feed and an inductive shorted line. To improve the isolation between two antennas, a suspended line with a parasitic element is employed. The isolation of the proposed antenna is higher than $18 \mathrm{~dB}$ within $1.75-2.66 \mathrm{GHz}$. With this high isolation and the orthogonal radiation pattern, a low enveloped correlation coefficient (ECC) can be also achieved from the far-field pattern calculation [9].

\section{Antenna Configuration and Design}

Figures 1 and 2 show the geometry and a photograph of the proposed antennas, respectively. The size of the ground plane is $45 \times 85 \times 1 \mathrm{~mm}^{3}$ and the size of the diversity antenna is $45 \times 15 \times 1 \mathrm{~mm}^{3}$. The proposed antennas are printed on top and bottom layers of FR4 $\left(\varepsilon_{r}=4.4\right)$ substrate, and the detailed dimensions are shown in Figures 1(b) and $1(\mathrm{c})$. The proposed antennas consist of a gap-coupled 


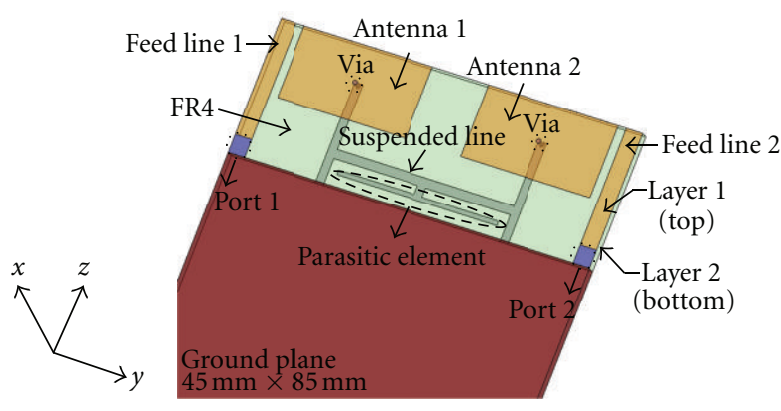

(a)

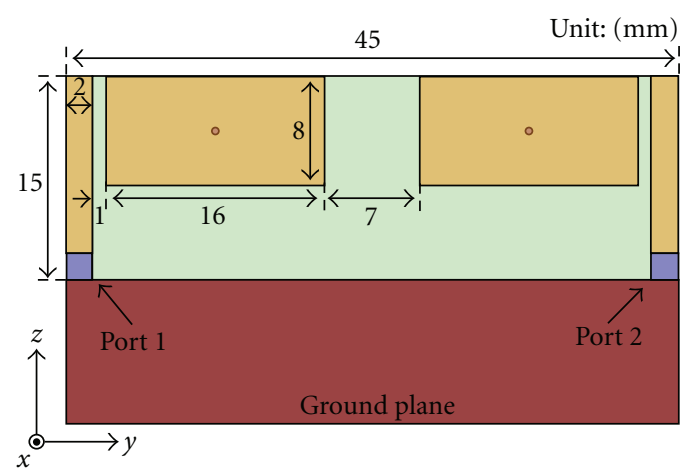

(b)

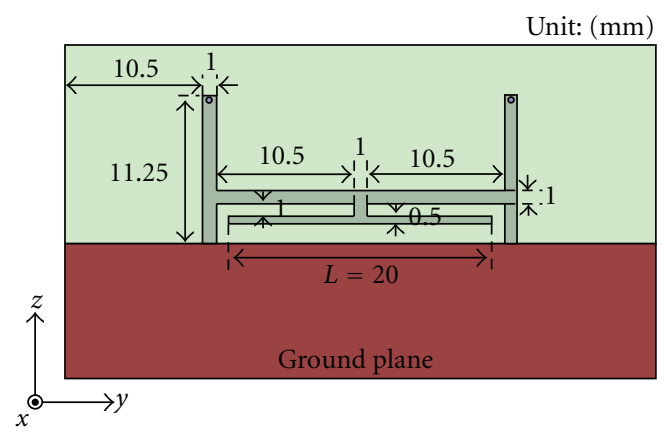

(c)

FIGURE 1: Geometry of the proposed antenna: (a) overall view, (b) detailed view of layer 1 (top), and (c) detailed view of layer 2 (bottom).
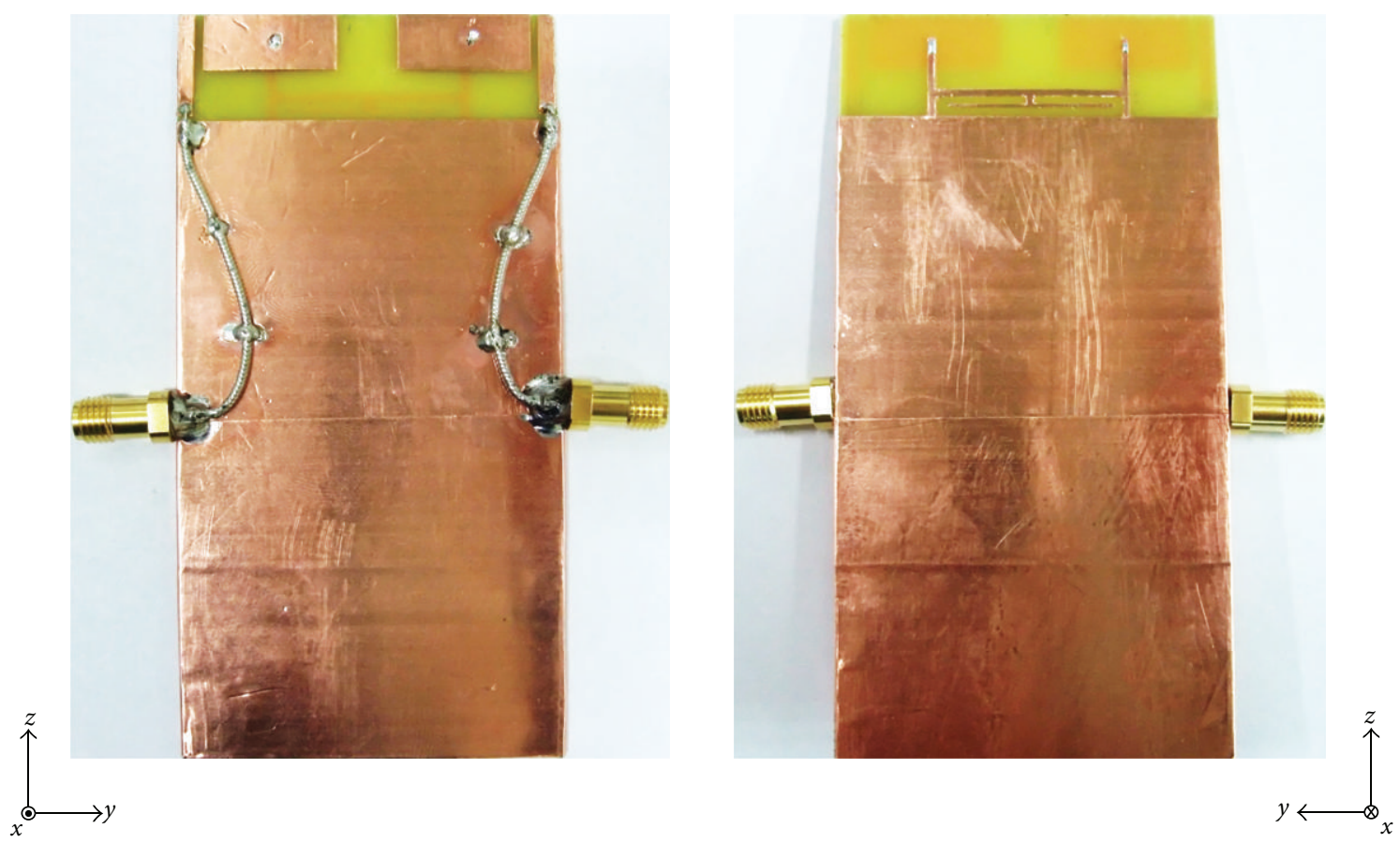

Figure 2: Photograph of the fabricated antenna. 


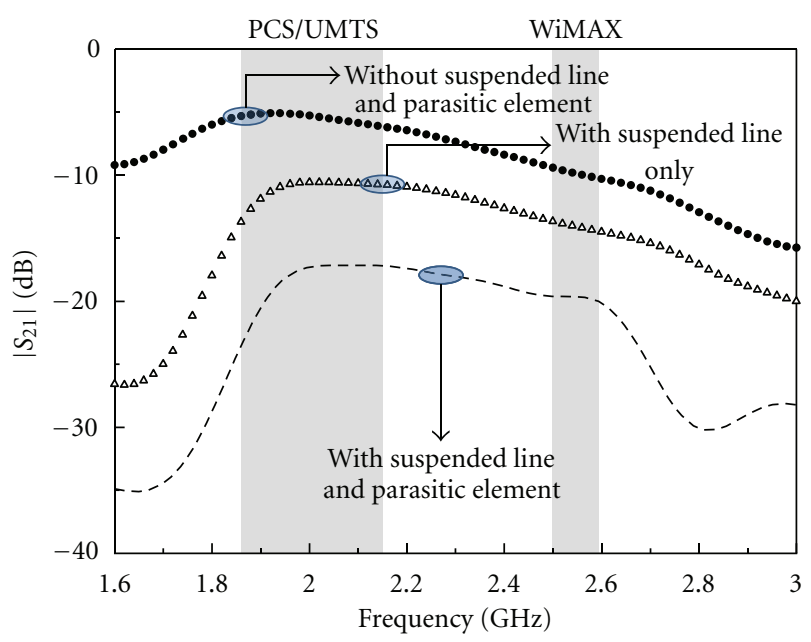

Figure 3: Simulated isolations $\left(S_{21}\right)$.

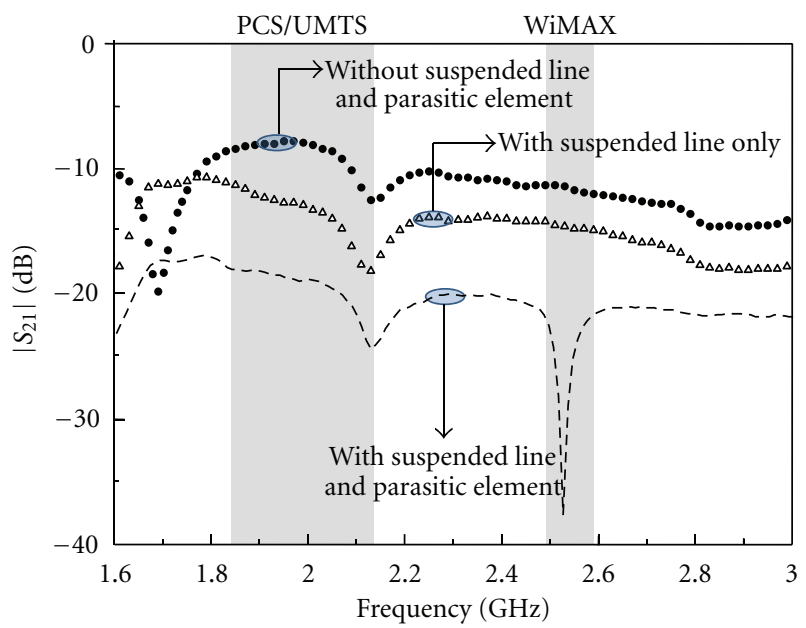

Figure 4: Measured isolations $\left(S_{21}\right)$.

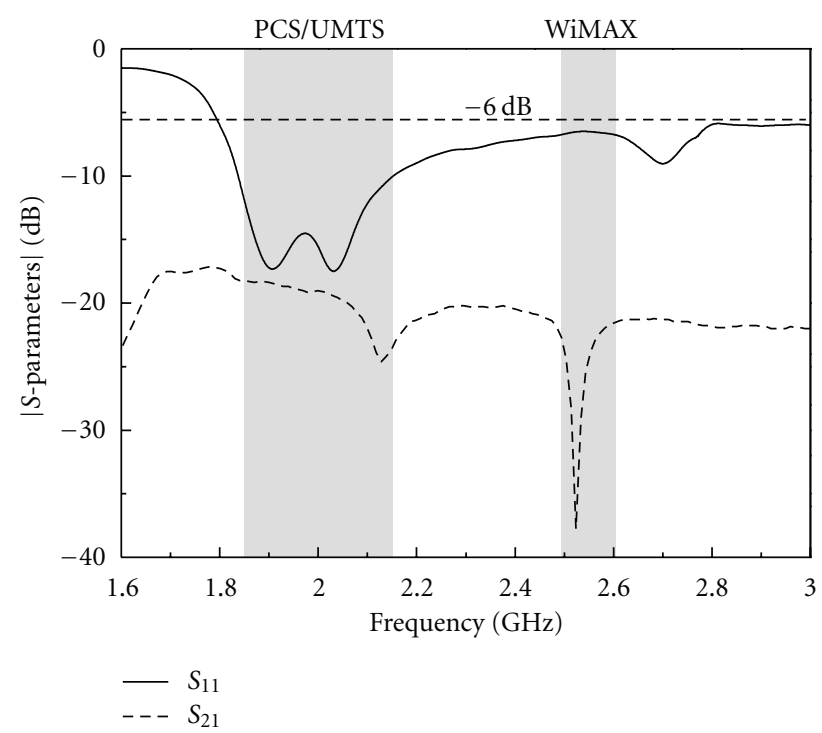

FIGURE 5: Measured S-parameters of the proposed antenna. 

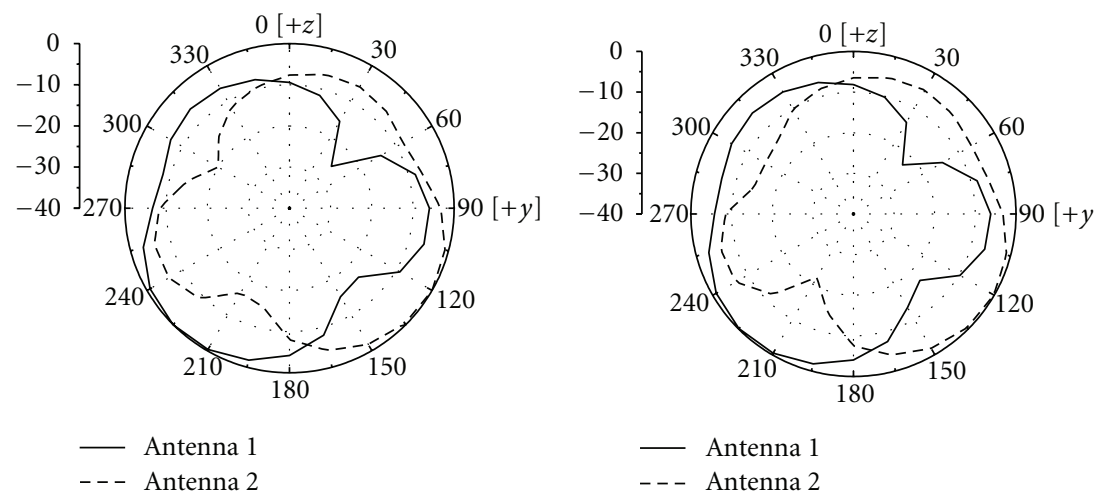

(a)
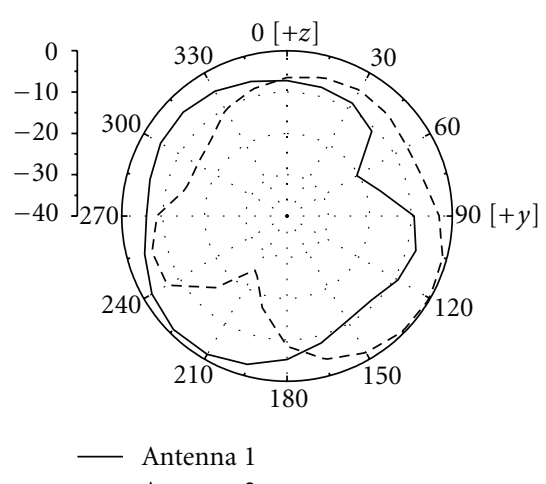

- - - Antenna 2

(c)

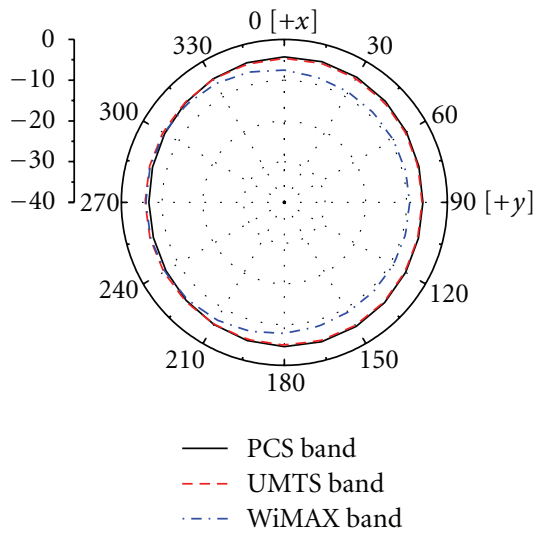

(d)

FIGURE 6: Measured radiation patterns: (a) $y z$-plane, PCS band, (b) $y z$-plane, UMTS band, (c) $y z$-plane, WiMAX band, and (d) $x y$-plane, PCS/UMTS/WiMAX bands when Antenna 1 is excited.

feed, an inductive shorted line, and a suspended line with a parasitic element. The gap-coupled feed and the radiator are printed on the top layer. The inductive shorted line and the suspended line with the parasitic element are printed on the bottom layer. The top and bottom layers are electrically connected via holes. To widen the bandwidth, we propose use of the inductively shorted line-connected monopole with a gap-coupled feed. The main function of the proposed inductively shorted line and the gap-coupled monopole is to provide triple resonance modes in a monopole. The first resonance mode originates from the quarter wavelength monopole. The second and third resonant modes are due to input impedance enhancement by the inductively shorted line and the gap-coupled feed. They provided capacitive compensation between the radiator and the ground plane to improve the input impedance matching of the second and third resonant frequencies. Finally, the frequencies of the triple resonances are close together and, hence, the proposed antennas achieve wide bandwidth. The suspended line positioned at the inductive shorted lines also enhances the isolation between two antennas. The suspended line actually acts as a neutralization device by picking up a certain amount of the signal on one antenna and feeding it back to the other. A particular combination of length and width of the suspended line can lead to a better isolation level. In addition, the parasitic element maximizes the antenna isolation. The proposed parasitic element operates as the open stub $(\lambda / 4)$, so that this parasitic element can suppress the surface current on the ground plane between the closely located two antennas.

\section{Result and Discussion}

Figures 3 and 4 show the simulated and measured isolations $\left(S_{21}\right)$ between two antennas without both the suspended line and the parasitic element, with the suspended line only, and with both the suspended line and the parasitic element. It demonstrates that a high isolation $(>18 \mathrm{~dB})$, which is generally accepted for practical applications in industries, can be achieved for all frequency bands, especially for the PCS and UMTS band, through adding the parasitic element on the suspended line. The measured reflection coefficients $\left(S_{11}\right)$ and isolation $\left(S_{21}\right)$ of the proposed antenna are shown in Figure 5. The proposed antenna can cover the PCS (1.85$1.99 \mathrm{GHz}) / \mathrm{UMTS}(1.92-2.17 \mathrm{GHz}) / \mathrm{WiMAX}(2.5-2.6 \mathrm{GHz})$ bands (VSWR $3: 1$ ) with a compact size and wide bandwidth. Figure 6 shows that polarizations of the diversity Antennas 1 and 2 are orthogonal to each other. They have been measured 


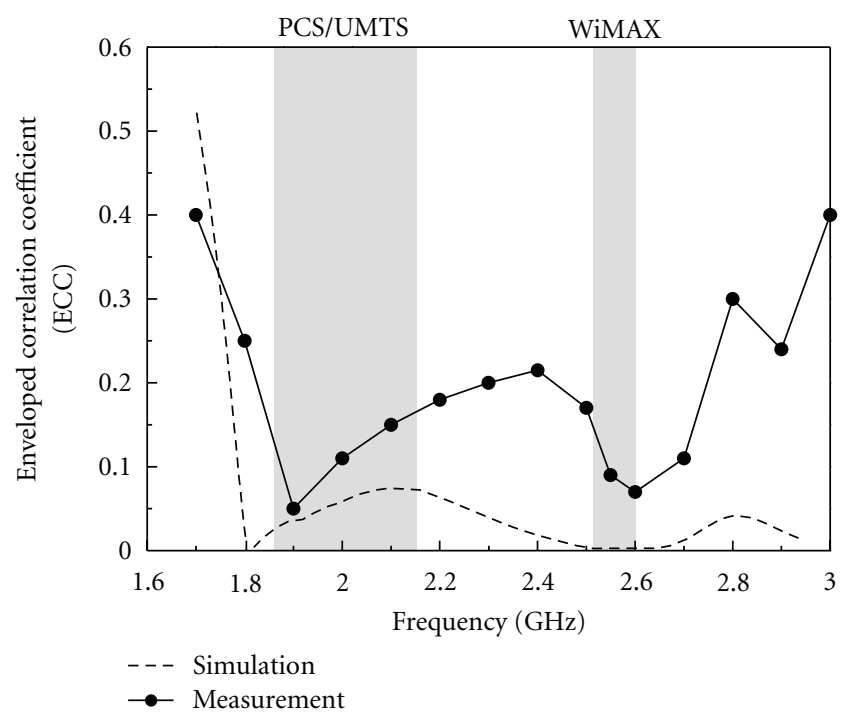

FIgURE 7: Simulated and measured ECC.

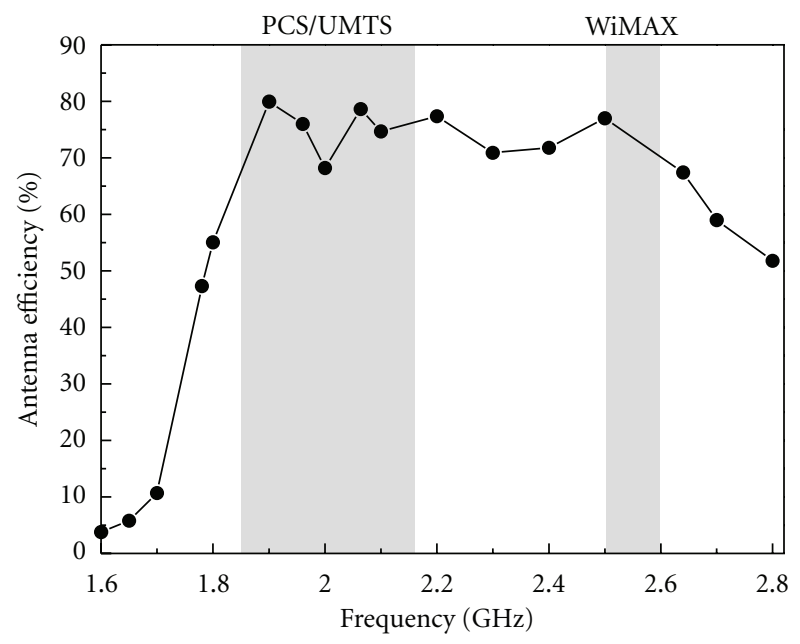

Figure 8: Measured efficiency of the proposed antenna.

with one antenna excited and the other terminated to a load with $50 \Omega$. In general, two antennas are orthogonally located to each other so that they can provide the polarization diversity and then reduce the mutual coupling between them. In this paper, a compact antenna for the polarization diversity is achieved by arranging two PIFAs linearly along the $y$-axis. The $E$-field directions of the proposed diversity antennas for PCS (Figure 6(a)), UMTS (Figure 6(b)), and WiMAX (Figure 6(c)) bands are diagonally orthogonal to each other even though two antennas are linearly (frontto-front) mounted with the suspended line and the parasitic element. Since these two symmetrical PIFAs have both vertical (due to current on the radiating element) and horizontal (due to current on the ground plane) $E$ field components, their $E$-field directions are diagonal and orthogonal to each other as shown in Figures 6(a), 6(b), and $6(\mathrm{c})$. Therefore, these orthogonal radiation patterns, and high isolation $(>18 \mathrm{~dB})$ give a very low ECC $(<0.2)$ of the proposed antenna as shown in Figure 7 . The proposed antenna has also a high efficiency of $>67 \%$ as shown in Figure 8 for all operating frequency bands.

\section{Conclusion}

A compact wideband diversity antenna is proposed for mobile phone applications. It has a very low profile, high radiation efficiency $(>67 \%)$, high isolation $(>18 \mathrm{~dB})$, and low ECC $(<0.2)$. The measurement results confirmed that the proposed antenna has a wide bandwidth through use of a gap-coupled feed and an inductively shorted line and that it also has good isolation performance through the use of a suspended line with a parasitic element. The operation frequency band (VSWR $3: 1$ ) of the proposed antenna is $1.78-2.8 \mathrm{GHz}(1.02 \mathrm{GHz} ; 45 \%)$ and includes a required 
triple service band of PCS (1.85-1.99 GHz), UMTS (1.922.17 GHz), and WiMAX (2.5-2.6 GHz).

\section{Acknowledgment}

The present research has been conducted by the Research Grant of Kwangwoon University in 2012.

\section{References}

[1] R. G. Vaughan and J. B. Andersen, "Antenna diversity in mobile communications," IEEE Transactions on Vehicular Technology, vol. 36, no. 4, pp. 149-172, 1987.

[2] G. Chi, B. Li, and D. Qi, "Dual-band printed diversity antenna for 2.4/5.2-GHz wlan application," Microwave and Optical Technology Letters, vol. 45, no. 6, pp. 561-563, 2005.

[3] A. C. K. Mak, C. R. Rowell, and R. D. Murch, "Isolation enhancement between two closely packed antennas," IEEE Transactions on Antennas and Propagation, vol. 56, no. 11, pp. 3411-3419, 2008.

[4] W. Yu, S. Yang, A. Tang, and M. H. Cho, "A new dual-band diversity antenna used for mobile phone," in IEEE International Symposium on Antennas and Propagation and USNC/URSI National Radio Science Meeting (APSURSI '09), June 2009.

[5] H. Li, J. Xiong, and S. He, "A compact planar MIMO antenna system of four elements with similar radiation characteristics and isolation structure," IEEE Antennas and Wireless Propagation Letters, vol. 8, pp. 1107-1110, 2009.

[6] A. Diallo, C. Luxey, P. Le Thuc, R. Staraj, and G. Kossiavas, "Enhanced two-antenna structures for universal mobile telecommunications system diversity terminals," IET Microwaves, Antennas and Propagation, vol. 2, no. 1, pp. 93-101, 2008.

[7] J. Byun, J. Jo, and B. Lee, "Compact dual-band diversity antenna for mobile phone applications," Microwave and Optical Technology Letters, vol. 50, no. 10, pp. 2600-2604, 2008.

[8] H. Bae, F. J. Harackiewicz, M. J. Park et al., "Compact mobile handset MIMO antenna for LTE700 applications," Microwave and Optical Technology Letters, vol. 52, no. 11, pp. 2419-2422, 2010.

[9] S. Blanch, J. Romeu, and I. Corbella, "Exact representation of antenna system diversity performance from input parameter description," Electronics Letters, vol. 39, no. 9, pp. 705-707, 2003. 

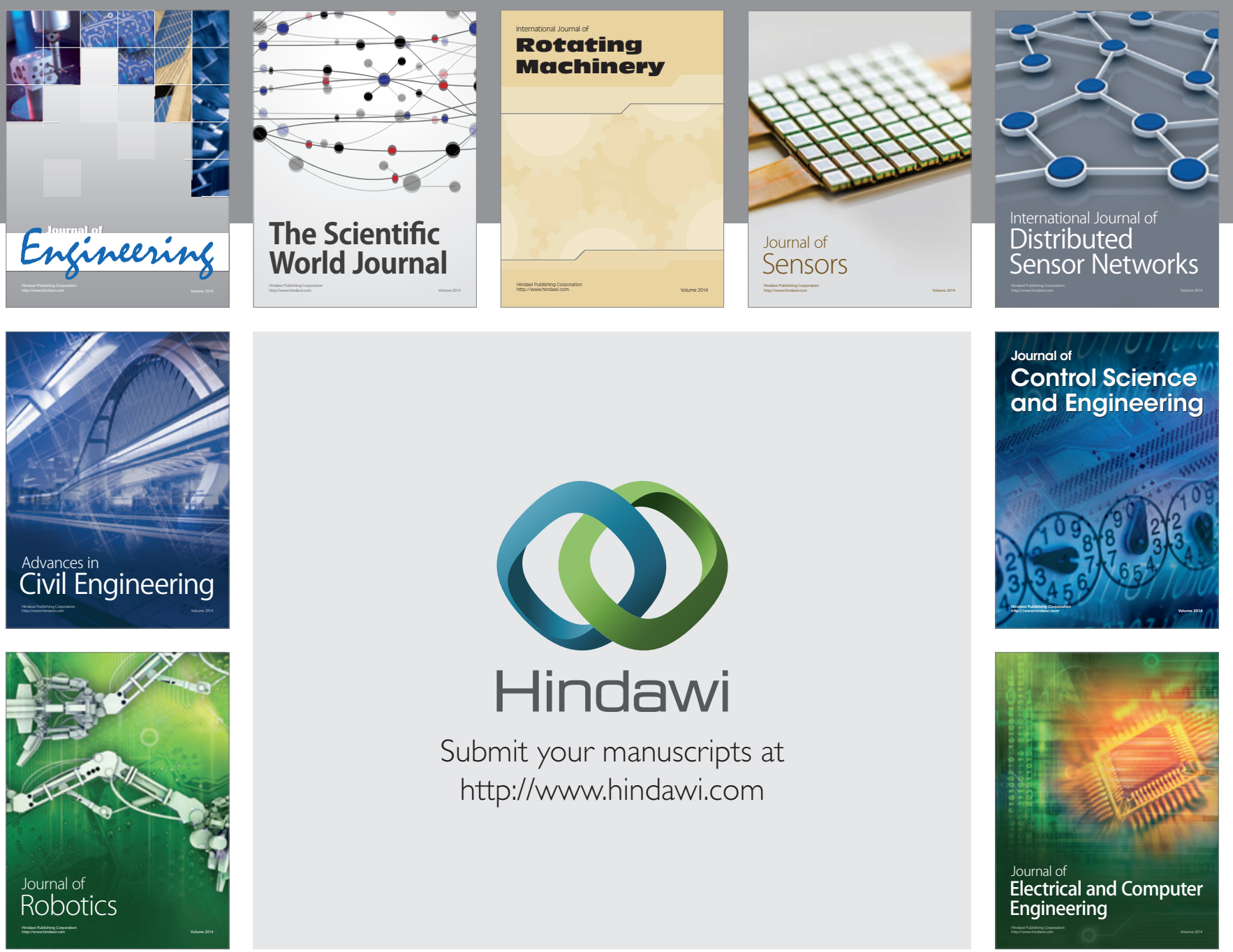

Submit your manuscripts at

http://www.hindawi.com
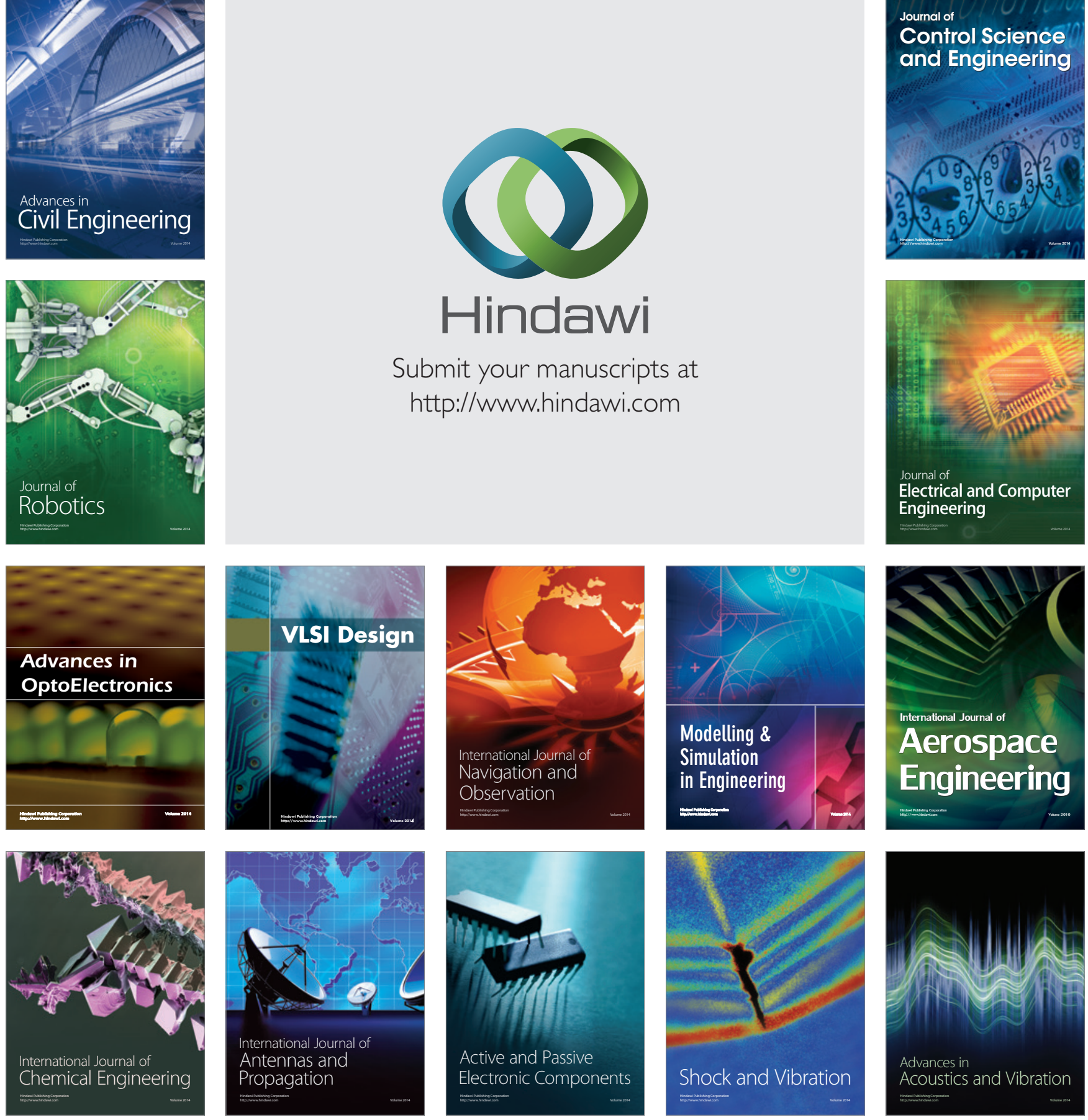